Information Management and Business Review

Vol. 2, No. 1, pp. 12-18, Jan 2011

\title{
Understanding and strengthening the health of family businesses in Laos
}

\author{
*John Walsh ${ }^{1}$, Nittana Southiseng ${ }^{2}$ \\ 1,2School of Management, Shinawatra University, Thailand \\ *jcwalsh@siu.ac.th
}

\begin{abstract}
More than $90 \%$ are family-businesses and are concentrated in retail, handicrafts, and personal services sectors. More than half are female-owned and managed, although baseline information about business and family management are limited. This paper reports on qualitative research aimed at understanding family business practices, impact of education in family businesses in a range of activities in Laos. Most such businesses remain based at or very close to home, and along the main road with any growth managed by hiring additional family members. Firms were run on traditional lines, while the management decisions were generally taken by senior family members depending on their existing prejudices. Although family businesses in Laos are still largely disorganized, they play critical roles in creating job opportunities and boosting household income for local residents as well as helping family members to utilize their existing talents, time, and resources. In promoting this sector, the Government of Laos has significant roles in developing policies, establishing a relevant governing agency, and encouraging training and involvement from the private sectors and from key international organisations.
\end{abstract}

Keywords: Business development, Entrepreneurial development, Family business, Laos, SMEs

\section{Introduction}

Despite recent evidence to the contrary, Laos remains a small and poor country. For example, in 2009, the World Bank reported that the real GDP growth of Laos reached 6.4\%, which was the second highest in the East Asian region after China. The most recent estimate of per capita GDP in Laos is $\$ 2,100$ - or the equivalent of $\$ 175$ per month. Laos was able to mitigate the direct impact of the world economic crisis starting in 2008 through sustaining the demand for Lao exports, including copper and gold destined for China, garment products for Europe and electricity for Thailand, as well as maintaining the tourism industry and overseeing the increase of expenditure associated with the construction of infrastructure to facilitate the 25 $5^{\text {th }}$ SEA (South East Asian) Games in Vientiane in December 2009 (Phouthonesy, 2010). However, the Laotian economy remains largely dependent on a small number of large foreign firms involved in resource extraction, government bodies, non-governmental organizations (NGOs) and aid organizations in addition to the great majority of enterprises, which are very small and often family-based. As indicated in the study of Phimmavong and Chanthavong (2009), the highest number of registered enterprises in Laos belongs to the trading sector (65\% of the total of economic units), followed by manufacturing (29\%), agriculture (3\%) and services (3\%). The great majority of the people involved in economic enterprises, in other words, are involved in petty trading of one sort or another. This ranges from market or street level vending to shopkeeping and more sophisticated operations also integrating manufacturing and distribution.

Small and Medium Enterprises (SMEs) in Laos are classified by turnover, assets and the number of employees: (1) micro enterprises have from 1-3 employees; (2) small enterprises are classified as those with an average number of employees not exceeding 19 persons, with total assets not exceeding 250 million kip, or an annual turnover not exceeding 400 million kip; (3) medium enterprises are those with an average number of employees not exceeding 99 persons, total assets not exceeding 1.2 billion kip or an annual turnover not exceeding 1 billion kip; (4) large enterprises are defined as having 100 staff or more. According to Souvannavong (2006), SMEs in Laos accounted for 95\% of all enterprises in the country. The SME sector comprised of $16 \%$ medium enterprises, $58 \%$ small enterprises, and $21 \%$ micro enterprises. More than $90 \%$ are family businesses and are concentrated in the retail, handicrafts and personal services sectors. Family businesses, in other words, dominate the economy in terms of numbers and employment and the majority of them are fairly basic in their operations. In a Lao economy that sees greater levels of competition as a result of increased circulation of goods; family-owned businesses are under greater pressure to remain competitive 
and to upgrade the quality of their offerings. Increased competitive pressure can have an impact on stress levels felt both by the business operator and by other family members. This makes it important, therefore, to understand the types of family business in operation in Laos and the pressures that they face, with a view to determining means of helping those businesses improve in sustainability and profitability. Consequently, this paper aims to explore and understand further the actual practices of family businesses in Laos. Firstly, the study identifies the general profile of family business entrepreneurs; secondly, it identifies the managerial characteristics of family business owners and the challenges they are currently facing. Finally, the study aims to identify the key factors that might improve the family businesses.

\section{Literature Review}

\section{What is a Family Business?}

Achieving an inclusive and accurate definition of a family business has proved problematic. Integrating a variety of different possible relevant areas of investigation, Astrachan, Klein and Smyrnios (2002) posited an F-PEC scale of authenticity that might be best described as belonging to the business studies tradition of eclectic paradigms. In a subsequent review of different types of family business, Howorth et al. (2010) considered the various parameters of family membership of a firm and the roles within it that might be taken. The elaboration of the link between the conceptually complementary concepts of family business and business family has also been undertaken (Litz, 2008). These complications have been avoided by the Lao government by adopting a simple but inclusive definition provided by the International Labour Organization (ILO). It is explained in the Study on Generating Employment through Micro and Small Enterprise and Cooperative Development in Lao PDR (ILO, 2006) that a family business is defined as a business owned and managed by one or more family members. With Lao culture emphasizing the values of collective action, family-operated businesses are attractive and this contributes to their prevalence among MSMEs. In a family business, enterprise owners and unpaid workers represent more than $90 \%$ of the MSME sector workforce. In addition, family businesses in Laos have two systems: the family system and the business system.

Family system: the decision-making characteristics of this system are generally influenced by 'emotional judgments'. A person's status is determined by seniority and position within family relationships. Her/his rewards are determined by personal honesty and loyalty. Being a member of the family means, of course, that she/he is a member of the business for life. Business system decision-making, on the other hand, tends to exclude emotional bias and the employee's status is determined by a particular kind of contract or by shares held in the business, both of which may well be temporary in nature. Rewards are based on performance and membership is based on qualification and is likely to be limited in time. Two common problems often found in this kind of system are miscommunication and conflicts among family members and the inability of parents to persuade their sons or daughters to succeed her/him in the ownership and leadership of the business. The family business system most commonly seen in Laos is clearly influenced by what is known as the Chinese family business (CFB), which features opportunistic diversification, autocratic decision-making, and spinning off new ventures for family members to take on as managers when they are ready for such responsibility or else to take advantage of emergent market opportunities. The CFB is characterized by nepotism, paternalism and family ownership (Wong, 1993). As a result of the long-term diffusion of Chinese principles and ethnic Chinese people, the CFB pattern and variants of it may be detected in many East Asian societies.

\section{Promoting Local Entrepreneurs in Laos}

Tham (2009a) reported in the Vientiane Times that the number of SME operations in Laos is increasing in size and performance is increasing in effectiveness despite the global recession. A total of $49 \%$ of 400 SMEs were growing in 2005, whereas 59\% of 500 SMEs experienced business growth in 2007. The Small and Medium Enterprises Promotion and Development Office (SMEPDO), an agency of the Lao government, has simplified the registration system for business start-ups. It appeared to be easier to navigate than in the past and not many documents are needed. SME expansion is seen as the backbone of economic growth of Laos and, consequently, it is believed that positive growth in the Lao economy depends on the development of this sector. Nevertheless, it is still the case that some businesses had to pay $3 \%$ of their investment cost to a middleman or broker for document work and to register for a license for the business start-up. This remains a 
significant figure. For this reason, the government has to pay attention to promoting and facilitating MSME growth quickly by improving legal frameworks to allow their establishment, together with establishing an online registration system in the fiscal year of 2009-2010 and a one-stop service unit for foreign investors at the Ministry of Planning and Investment. According to economic data from 2006, 83\% of Lao workers were employed in a total of more than 126,000 SMEs. This means SMEs contribute to both national economic development and employment generation in Laos. However, Tham (2009b) reported that SMEs still needed to acquire investment funding from banks and financial institutions, which tended only to provide short-term funding. It is also the case that active people in SME research are still limited to a small group numerically. The Laotian economy operates in a framework of developing infrastructure orchestrated by the Asian Development Bank (ADB) with a view to creating a transportation network linking east, west, north, and south of the Greater Mekong Sub-Region with external markets and places of production. This should help to promote a variety of positive developmental outcomes (ADB, 2010).

\section{Methods}

This study integrated both secondary and primary data. To understand the actual practices and managerial characteristics of family business entrepreneurs in Laos, 48 in-depth personal interviews were conducted during June 2010, within the confines of Vientiane Municipality in Laos. The respondents were selected to be diverse in nature and were involved in various business areas. The respondents were family-owned business operators and were randomly selected according to a snowball technique and according to the convenience of the interviewees. It is believed that this approach, in combination with the primary data and direct observation, has enabled the researchers to establish trust with the interviewees so that they only rarely hesitated to share detailed experiences and figures.

Prior to the data collection, a semi-structured survey was prepared in English and interpreted into Lao in order to ensure a high level of understanding during the interviews. At the same time, the researchers were able to identify additional information and data based upon what was discussed during the interviews. The interview was certainly carried out in the native language of the respondents (Lao) and extensive notes were taken during the interviews for subsequent transcription and analysis. Consequently, the validity and reliability of the obtained information during the interviews appears to be sufficiently high and also conforms to expectations formed by familiarity with the existing literature. Content analysis methods - tools for measuring the semantic content of communications - were chosen to analyze the obtained data by the research team which was also involved with data collection, in compliance with anonymity protection and academic purposes. It is believed that the quality of the data obtained is appropriate and previous research projects and papers have followed essentially the same method successfully.

\section{Findings and Discussion}

This section of the paper presents a brief profile of the respondents, their families, and businesses. Following these profiles will be an investigation of the actual practices involved in managing family businesses, the challenges inherent in family business management, the factors necessary to enhance the capability of family businesses in Laos and, finally, the future prospects of the samples for their business management and growth.

\section{Family Business Entrepreneurs' Personal Profiles}

Forty-eight (48) respondents were interviewed face-to-face individually. All of them are based in Vientiane municipality, the capital city of Laos, where the strategic and national administrative organs of the country are located. Out of 48 respondents, $97.6 \%$ were Lao and the other was Chinese. Most (29) of the respondents were female and 19 were male. 46 respect the Buddhist religion and the other two identified themselves as Christian. The respondents were varied in age. They were grouped in four age-groups: 1 was younger than 20 years old, 20 were 21-35 years, 23 were 36-55 years, and 4 were 56 years and up. 40 respondents are married ( 1 had been divorced) and 8 are single. Most (28) of them appeared to be part of a big family as they had 5-10 members in the family, 11 had four, 4 had three, 3 had 2, and 2 had more than 10 family members. 40 respondents said their family members included their spouse (husband or wife). Apart from the spouse, 
they were staying with children, parents, brothers/sisters, nieces/nephews, cousins, in-laws and various assistants employed in their businesses.

A large number (37.5\%, comprising $25 \%$ males and $12.5 \%$ females) of respondents had acquired vocational degrees, $31.3 \%$ (2.1\% males and 29.2\% females) acquired only high school degree graduation, or lower, $29.2 \%$ (12.5\% males and 16.7\% females) held undergraduate degrees and $2.1 \%$ of women had a graduate level degree. This indicates that more women in Laos have started to recognise the importance of education and was, also, able to access opportunities for their personal educational development. The major of their educational qualification was mostly in the fields of business administration and management (accounting for 18.8\%). The remainder was involved in the diverse areas of IT, law, education, accounting and finance, medicine and health, English and agriculture and forestry.

$35.4 \%$ were very certain that their educational backgrounds were useful in their family business management at the level of $81 \%-100 \%$; $50 \%$ were confident that their education played important roles in helping them execute their businesses (at the level of 41\%-80\%); $10.4 \%$ replied that they had utilized learned knowledge in administering their family businesses (at the level of $21-40 \%)$. The remainder (4.2\%) believed that their education helped to contribute to their business management to a limited extent only. In this regard, the study particularly indicated that many female respondents were more likely to feel that education did positively contribute to their businesses management and growth (60.4\% said this).

\section{Family Business Entrepreneurs' Business Profiles}

Of course, all respondents were members of family-based businesses, of which $89.6 \%$ were soleproprietorships and $10.4 \%$ were partnerships. 43 respondents had officially registered their business operation and the rest did not register, even though the enterprise and business law of Laos clearly stated that business-oriented enterprise are required to register officially prior to operating their businesses in Laos. Inevitably, the decision to become legal is a complicated one for all business operators as there must be a balance between paying tax and meeting government regulations on the one hand and the benefits of receiving government services on the other hand. According to what respondents have self-reported therefore, most respondents seem to think that official registration is a preferable option (since it is more difficult to revert to unofficial status from official than vice versa). The respondents of this study have been involved in varied types of businesses such as tourism, restaurants and food production, community groceries, garment manufacturing, construction materials, furniture, import-export, handicrafts, electronic products and services, stationery, internet service provision and others. In this case, a majority of respondents have been engaged in the grocery businesses $(27.1 \%$ of the total). This type of business was more likely to be visible in most corners of Vientiane municipality: local markets, main roads, university, tourist, or office areas. This was observed by one of the authors during the data collection phase.

The respondents were also questioned about the sources of their products or raw materials and 31 respondents replied that their products were mostly imported from Thailand. Apart from Thailand, products and raw materials were sourced from local suppliers in Laos, China, Vietnam, and India. The reasons for running the current businesses were investigated and it was found that a majority of the respondents said it was their ambition to run such a business because they like it; some wished to use their talents, knowledge or experiences to establish their own businesses; the business was transferred from parents; a business opportunity was identified as there are not many existing sellers; low capital to invest in such business; the business introduced newly sourced products or services to the market, and some other reasons. The businesses investigated in this study were mostly located at home. Besides the home as the location for business premises, others were located along the main road because it was easier to be visible to the customers or general travelers on the roads. The market was another place where the respondents of this study were located. These respondents explained that the market was the only suitable location for them to be able to attract customers, especially tourists. The final reason was the location of the business in an area identified as being part of a tourist area, in which one respondent said that was a potentially profitable location for the business. 


\section{Business Capital and Revenue}

23 respondents said that the initial capital invested in their family business was not high, being between UD\$1,001-10,000; 9 had invested in their start-up business not more than UD\$1,000. 8 started up their business with initial capital of around UD\$10,001-50,000, while 2 had invested more than UD\$100,000 as start-up capital. The remaining respondents were not comfortable with sharing this type of information. Discussing family business performance, respondents were questioned about their monthly average revenue. Inevitably, this was an area of discussion into which not every respondent was willing to enter. Even so, 42 (87.5\%) out of 48 respondents willingly answered the question. Of the willing, 17 earned UD $\$ 500$ or less per month, 13 got UD\$1,001-5,000, 7 got UD\$501-1,000, 3 got more than UD\$10,000 and the other two got UD $\$ 5,001-10,000$. It might be noted here that the average salary in Vientiane is little more than the US $\$ 2$ per day (US $\$ 60$ per month, therefore) determined by the World Bank to be the minimum below which poverty exists. In this case, it is observed that most of the businesses used a small amount of capital to start-up their businesses, particularly below UD $\$ 10,000$. Some respondents said that they had started up their businesses more than 15 years previously and some had invested in a business that did not acquire a large amount of capital. Meanwhile, a majority of respondents (25) were able to earn average revenue of more than UD\$500 monthly. In comparison to the most recent estimate of per capita GDP in Laos, which is estimated to be around $\$ 2,100$ - or the equivalent of $\$ 175$ per month, it indicates the profitability of entrepreneurialism in this context as reported by respondents.

\section{Managerial Characteristics of the Family Business}

In studying the management style of family business entrepreneurs, out of 48 valid responses, $95.8 \%$ used the money gained from their family businesses on both business operations and family matters; $81.3 \%$ answered that the day-to-day management of the family business was the responsibilities of family members. $75 \%$ said that the procedure of business decision making was simple and it was possible to make decisions quickly. More than $50 \%$ of respondents said that they often added capital to sustain business performance and that the efficiency of their businesses was dependent on receiving sufficient attention from family members. Stakeholders or family members still appear to lack the marketing ability to promote and attract customers to their businesses. The family elder normally acts as the senior manager of the family business, according $50 \%$ of the respondents, although $43.8 \%$ believed that they still lack leadership ability to lead the business in such a competitive environment. In addition, $37.5 \%$ of the respondents added that the personality and emotions of family members variously represented positive or negative influences on the management of family business. Generally, the first child of the family was assigned to be permanently responsible for the family business, although other family arrangements were also exhibited.

\section{Challenges of Family Business}

During the interviews, the types of challenges that family business entrepreneurs often face were also investigated. The principal problem reported was of competition: $95.8 \%$ of respondents said that local competitors were increasing in number and more than $70 \%$ said that many similar businesses were entering and operating in the local market. As a result, customers had increasingly high bargaining power as numerous substitute companies and products were available to them. Additionally, more international investors have started taking part, particularly those from Thailand, Vietnam, and Chinese. More than $54 \%$ observed that family business entrepreneurs still required more of their existing limited set of skills in managing a business operation in a competitive environment, while also having only inadequate capital to enlarge the business. Last but not least, $14.6 \%$ declared that the business in Laos could not easily adapt in accordance with the market mechanism and that the customers commonly bought the products for their basic needs. Out of 48 respondents, $43.8 \%$ answered that they previously obtained information about the development of family business, although $97.9 \%$ responded that they have never received any support from the relevant authorities, agencies, NGOs or others to improve their firms; only $2.1 \%$ seldom got support from those organizations. However, it is obvious that the respondents did receive support because the respondents joined a commercial association which normally brought together the members of the association to promote and sell their products in various provinces of Laos and some international countries, such as Thailand, Japan, Malaysia and others. 
Regarding the application of modern technologies to enhance the efficiency of family business operations and management, $47.9 \%$ of respondents recognized the important roles of technology and applied some aspects of technology in their business administration and management processes. Computers, for example, are used in the family business in recording the business accounting and finance transactions by $20.8 \%$ of respondents, while $12.5 \%$ used some modern technology machinery, such as sewing machines, to enhance the efficiency of their businesses. Another $10.1 \%$ have used internet, fax and phone for contacting customers, suppliers, business shareholders or employees of the business.

\section{Key Factors in Improving Family Business Development}

Three fourths (3/4) of respondents strongly agreed that the family business entrepreneurs should be confident, diligent and passionate about what they were doing and put their focus on providing good service to their customers. More than half (2/4) of the respondents felt that it was highly important to have adequate capital and energy, to be able to seek opportunities and to get ready to provide a variety of products/services to the customers in the market. In the meantime, they also pointed out that it would be better for the family business entrepreneurs to acquire fundamental business management background skills such as marketing and finance so as to manage their firms efficiently. For those employed or to employ employees, hiring the right people in accordance with the business need and rewarding their contributions fairly were other critical tasks for the family business owners. Solving problems openly and honestly as well has having a clear understanding of the family business goals and concepts of the business direction were also considered important factors by respondents. Most respondents were in agreement with all of these points.

In addition, the authors also found that three fourths (3/4) of the respondents moderately believed that inspiring the young members in their family to acquire business-oriented skills so that they could subsequently lead the family business and perhaps to enhance its positive performance. At the same time, the family business entrepreneurs were to be brave to be initiators and innovators, not followers in introducing diverse products and services to the customers. There was also a moderate consensus from two thirds of the respondents that it was more beneficial for those who obtained experience from involvement in the business sector. This would possibly help them not get frustrated in decision-making concerning immediate issues. In reinforcing the performance of the family business, entrepreneurs should accept other people's involvement and creative ideas and should share information with others. Last but not least, it is suggested quite mildly that the family business entrepreneurs should keep a clear distinction between business bank accounts and family accounts.

\section{Conclusions and Recommendations}

According to the findings described above, it is possible to conclude that family business entrepreneurs in this study obtained various experiences, used varied management styles depending on the context of the business which they operated and faced distinctive challenges and opportunities. In this regard, a majority (64.6\%) planned to continue running the day-to-day operations of their firms and $56.3 \%$ had certain plans to expand their business to other markets, such as by opening new branches or expanding to other districts or provinces. $43.8 \%$ expected to provide more choice of products/services available at their business and $6.3 \%$ anticipated focusing on the current business by running the business with a properly established and organized plan to meet customers' expectations. $2.1 \%$ wished to transfer the current business to the next generation and then to establish new and alternative businesses. Meanwhile, it is noted that none planned to end up their business very soon. In this respect, it is possible to interpret that the respondents of this study have been enjoying their earnings from the business and they were reasonably satisfied by their business performance. Many of them even found opportunities to expand and enhance the growth of their businesses. Thus, the authors would like to recommend that the government of Laos should keep investing in developing local entrepreneurs by improving high quality entrepreneurs in the different fields available for firms. Allocating and seeking funds to support human resource development in various means such as training, business development services, mentoring and consultations for business sector are also important for the success of local entrepreneur development. It is also critical for the government or its representatives to improve entrepreneurial training content in colleges and universities in order to achieve the optimum returns on investment over the medium and long terms. 
For those stakeholders directly involved with family businesses, it is evident that market-based learning and analysis will be beneficial in addition to the prevalent East Asian tendency to look first to the public sector to provide opportunities for improvement. In general, it might be expected that the state, in moving more towards a capitalist economic system, will begin to rein back its activities such that it attempts to guarantee a level playing field for all actors in a more or less open and free market space. This, of course, will take some time to develop and, in the meantime and perhaps permanently, the Lao government can be expected to provide support for family businesses in conjunction with aid donors. Strengthening personal abilities and knowledge, in addition to the need for capital, remains of the greatest importance, as well as market development activities.

\section{References}

Asian Development Bank (ADB) (2010): Development Effectiveness Brief: Lao PDR at the Crossroads of Change. Manila: ADB. Available: http://www.adb.org/Documents/Brochures/Development-EffectivenessCountry-Briefs/decb-lao.pdf.

Astrachan, J. H., Klein, S. B. and Smyrnios, K. X. (2002): The F-PEC scale of family influence: A proposal for solving the family business definition problem, Family Business Review, 15/1: 45-58.

Howorth, C., Rose, M., Hamilton E. and Westhead, P. (2010): Family firm diversity and development: An introduction, Family Business Review, 28/5: 437-51.

International Labour Organization (2006): Study on Generating Employment through Micro and Small Enterprise and Cooperative Development in Lao PDR. Retrieved 8 July 2010, from http://www.ilo.org/public/english/region/asro/bangkok/ability/msme_lao_02_06.htm

Litz, R. A. (2008): Two-sides of a one-sided phenomenon: Conceptualizing the family business and business family as a Möbius strip, Family Business Review, 28/3: 217-36.

Phimmavong, B. \& Chanthavong, V. (2009): Challenges and Opportunities for Lao PDR's Small and Medium Forest Enterprises (SMFEs), Food and Agriculture Organization of the United Nations. Laos

Phouthonesy, E. (2010): Lao economic growth second in East Asia. Vientiane Times. http://www.asianewsnet.net/news.php?id=9754\&sec $=2$

Souvannavong, O. (2006): Information of SMEs in Laos. Regional Seminar on Information of SMEs in GMS Countries, 20-21 July 2006, PRC. Retrieved 7 July 2010 from http://www.slideshare.net/laoplanet/smesin-laos

Tham, S. (2009a): SMEs Gather Strength with Improved Registration. Vientiane Times. Issue 251, p.8. Retrieved 8 July 2010, from http://hrdme.wordpress.com.

Tham, S. (2009b): Lao SMEs Needs More Support. Vientiane Times. Issue 251, p.8. Retrieved 8 July 2010, from http://hrdme.wordpress.com.

Wong, S. L. (1993): The Chinese family firm: A model, Family Business Review, 6/3, 327-40. 